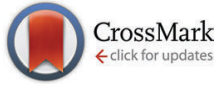

Cite this: Phys. Chem. Chem. Phys., 2015, 17, 23236

Received 29th April 2015, Accepted 5th August 2015

DOI: $10.1039 / c 5 c p 02512 e$

www.rsc.org/pccp

\title{
The use of carbon monoxide as a probe molecule in spectroscopic studies for determination of exposed gold sites on $\mathrm{TiO}_{2} \dagger$
}

\author{
Giacomo M. Lari, Ewa Nowicka, David J. Morgan, Simon A. Kondrat and \\ Graham J. Hutchings*
}

\begin{abstract}
The sol immobilisation technique, in which a stabilising ligand (such as polyvinyl alcohol or polyvinyl pyridine) can be used to tune metal particle size and composition, has become a valuable method of making supported nanoparticle catalysts. An unfortunate consequence of the stabilising ligand is that often access of reactant molecules to the metal nanoparticle surface is impeded. Several methods have been proposed for the removal of these ligands, though determination of the degree of their success is difficult. Here, we demonstrate the use of in situ infrared and UV-Vis spectroscopy to elucidate the access of carbon monoxide to the surface of $\mathrm{Au} / \mathrm{TiO}_{2}$ catalysts before and after various ligand removal treatments. These were contrasted with a catalyst prepared by deposition precipitation prepared in the absence of stabilising ligand as a control. Changes were observed in the infrared spectrum, with the wavenumber of carbon monoxide linearly bonded to Au for catalysts shifting before and after ligand removal, which correlated well with the activity of the catalyst for carbon monoxide oxidation. Also the extent of shifting of the Au surface resonance plasmon band on the addition of carbon monoxide, observed by UV-Vis, also correlated well with catalyst activity. These simple methods can be used to determine the quantity of exposed metal sites after a ligand removal treatment and so determine the treatments effectiveness.
\end{abstract}

\section{Introduction}

Supported gold catalysts have received considerable attention in the last decade, with the number of related publications increasing significantly since the seminal work by Haruta on sub-ambient CO oxidation and Hutchings on acetylene hydrochlorination. ${ }^{1,2}$ Supported gold catalysts have since been reported for many reactions, such as epoxidation, ${ }^{3}$ hydrogen peroxide synthesis, ${ }^{4}$ selective oxidation of hydrocarbons ${ }^{5}$ and alcohols. ${ }^{6}$ Catalytic activity of gold nanoparticles is known to be affected by a number of parameters, including metal support interactions and particle size. Therefore many methods, such as wet impregnation, ${ }^{7}$ incipient wetness, ${ }^{8}$ deposition precipitation, ${ }^{9}$ sol immobilization, ${ }^{10}$ colloidal deposition ${ }^{11}$ and physical grinding of acetate salts, ${ }^{12}$ have been developed. All of these methods have their significant advantages as well as disadvantages; for example

Cardiff Catalysis Institute, School of Chemistry, Cardiff University, Main Building, Park Place, Cardiff, CF10 3AT, UK. E-mail: hutch@cardiff.ac.uk;

Fax: +44 2920-874-030; Tel: +442920874059

$\dagger$ Electronic supplementary information (ESI) available. See DOI: 10.1039/ c5cp02512e

\$ Present address: Institute for Chemical and Bioengineering, ETH Zurich, Vladimir-Prelog-Weg 1, CH-8093 Zurich, Switzerland. the wet impregnation method is relatively simple method, but results in broad nanoparticle size distributions with some particles being $>20 \mathrm{~nm}$. On the other hand, the sol immobilization technique, which uses stabilising ligands (e.g.: polyvinyl alcohol (PVA) or polyvinyl pyridine (PVP)) to control particle size and distribution with great accuracy, has a different set of problems and challenges. Frequently the stabilizer ligands block the active sites and act as a physical barrier to the diffusion of reactants to the catalytically active metal surface. Though these catalysts have high activity, their full potential is often not realised until ligands have been removed by thermal decomposition, solvo-thermal treatments or electrochemical cleaning. ${ }^{13-15}$

Thermal decomposition methods are effective for the removal of any stabilizing agent, though an inevitable side effect would be metal particle agglomeration. Hutchings and co-workers demonstrated the effective removal of PVA from titania-supported gold catalysts using a reflux method with water. ${ }^{16}$ However, the method was unsuccessful for the removal of PVP. ${ }^{16}$ An alternative approach reported by Ansar et al., who used treatment with $\mathrm{NaBH}_{4}$, successfully removed PVP and organothiols from gold sols as evidenced by surface enhanced Raman scattering and UV-Vis spectroscopy. ${ }^{17}$ This PVP removal process has, however, yet to be successfully demonstrated with supported stabilised nanoparticles. 
The removal of capping molecules by various treatments and the subsequent accessibility of the metal surfaces is frequently determined by performing test catalytic reactions. ${ }^{18}$ Comparison of reaction results before and after treatment of catalysts is used to demonstrate the efficiency of the ligand removal procedure. Though this process is perhaps the most practical, as it focuses on the catalytic benefit of the treatment, it provides no direct information on ligand removal or ligand-metal interaction. Alternatively, spectroscopic techniques can be used to determine ligand concentration before and after treatment, with Hutchings and co-workers ${ }^{16}$ demonstrating a decrease in the intensity of Raman bands associated with PVA after the reflux treatment of catalysts in water. ${ }^{16}$ UV-Vis has also been used to monitor the desorption of PVP and organothiols from colloidal Au nanoparticles, induced by $\mathrm{NaBH}_{4}$ washing. ${ }^{17}$ Detailed spectroscopic analysis of the capping molecules is, however, often difficult, due to the relatively low concentrations of ligand within the catalyst. In addition, quantification of species adsorbed on surfaces, as is the case with capping agents, is challenging due to the effect of surface-capping agent interactions. A simpler method to determine changes in capping molecule concentration is the use of temperature programmed techniques, which is informative in providing evidence for absence of capping agent after treatment. ${ }^{19}$ However, temperature programmed techniques do not provide direct information on surface exposure or molecular access to the active site.

A third possibility in elucidating the effect of ligand removal treatment could be to selectively probe the metal nanoparticle itself with a suitable molecule. A recent study by Wu et al. noted in an in situ IR study that CO did not adsorb on Au thiolate clusters until the thiolate complexing agent was removed. ${ }^{20}$ The adsorption of $\mathrm{CO}$ on metal surfaces is very well known and has been well-studied with both infrared and ultraviolet-visible spectroscopy, and many studies correlate the adsorption spectra of $\mathrm{CO} /$ gold with the activity of the catalyst for $\mathrm{CO}$ oxidation. Yates et al., in the late 1960s, noted that a band associated with CO adsorbed on $\mathrm{Au} / \mathrm{SiO}_{2}$ shifted to lower wavenumbers at higher CO partial pressures. ${ }^{21}$ Dumas et al. then showed, in pioneering vibrational spectroscopic studies, that the shift observed at higher coverage was formed from two components: a chemical one, due to adsorbate:adsorbant interaction and a coupling component. ${ }^{22}$ A total shift of $-13 \mathrm{~cm}^{-1}$ was observed from $2125 \mathrm{~cm}^{-1}$ at low coverage to $2112 \mathrm{~cm}^{-1}$ at higher coverages, with the chemical contribution accounting for $-30 \mathrm{~cm}^{-1}$ and the coupling for $+17 \mathrm{~cm}^{-1}$. Further studies in this field have investigated wider $\mathrm{CO}$ partial pressure ranges, ${ }^{23}$ a range of catalysts prepared by different techniques, ${ }^{24-26} \mathrm{CO}$ adsorption on different Au surfaces, ${ }^{27}$ the effect of positively polarised sites on CO band position (shifts band to high $2128-2135 \mathrm{~cm}^{-1}$ range $)^{28,29}$

Another technique which can be applied for studies of gold supported nanoparticles is UV-Vis spectroscopy, which can take advantage of the surface plasmon resonance (SPR) effect observed with gold. As a surface effect, the SPR frequency is very sensitive to changes in the environment and material structure making it very well suited for applications in gas sensing. ${ }^{30}$ Haruta and co-workers applied supported gold nanoparticles $\left(\mathrm{Au} / \mathrm{CuO}\right.$ and $\left.\mathrm{Au} / \mathrm{Co}_{2} \mathrm{O}_{3}\right)$ as gas sensors for $\mathrm{CO}$ and $\mathrm{H}_{2} \cdot{ }^{31-33}$ A linear relationship between $\mathrm{CO}$ concentration and variation in absorbance associated with SPR was established, with a small red shift of the band being observed on CuO. Sirinakis et al. also demonstrated the possibility of sensing $\mathrm{CO}$ at high temperature (above $400{ }^{\circ} \mathrm{C}$ ) using gold on yttrium stabilised zirconia by monitoring the shift in frequency of the SPR. ${ }^{34}$

Here we report on the use of infra red and UV-Vis spectroscopy alone and also with $\mathrm{CO}$ as a probe molecule to determine the exposed Au coverage of $1 \mathrm{wt} \% \mathrm{Au} / \mathrm{TiO}_{2}$ catalysts, prepared by solimmobilisation, before and after reflux or thermal treatment. The study extends the work of Wu et al. ${ }^{20}$ by correlating the IR CO band position to surface coverage as opposed to discrete data that notes only the presence or absence of $\mathrm{CO}$ adsorption. This will be coupled with in situ UV studies that correlate SPR band shifts, associated with $\mathrm{CO}$ surface concentration, to the exposed $\mathrm{Au}$ coverage. The initial work shows the limitation of IR and UV-Vis studies alone in determining changes on catalyst treatment. This is followed by in situ CO probe studies, which provide much more information on the exposure of Au sites after catalyst treatment.

\section{Experimental}

\section{Materials}

$\mathrm{TiO}_{2}$ (Degussa P25), was obtained from Evonik. PVA $\left(M_{\mathrm{W}} 10000\right.$, $80 \%$ hydrolysed), PVP $\left(M_{\mathrm{W}} 10000\right), \mathrm{NaBH}_{4}$ were purchased from Sigma Aldrich, $\mathrm{HAuCl}_{4}$ was received from Johnson Matthey. Ammonium hydroxide (30 wt\%) was purchased from Fisher Scientific. CO (5000 ppm in $\mathrm{N}_{2}, 99.9 \%$ ) was purchased from BOC. All chemicals were used as received.

\section{Catalyst preparation: $1 \% \mathrm{Au} / \mathrm{TiO}_{2}$}

Deposition precipitation catalysts were prepared using a method detailed in the literature. ${ }^{35}$ First, the required amount of gold solution $\left(\mathrm{HAuCl}_{4} \cdot 3 \mathrm{H}_{2} \mathrm{O}, 6 \mathrm{mg} \mathrm{ml}{ }^{-1}\right)$ was added to $120 \mathrm{ml}$ of deionized water and stirrer for $10 \mathrm{~min}$. Then required amount of support $\left(\mathrm{TiO}_{2}, 1.98 \mathrm{~g}\right)$ was added to the solution to form a slurry. The $\mathrm{pH}$ was adjusted to 9 with dropwise addition of $0.5 \mathrm{M} \mathrm{NH}_{4} \mathrm{OH}$ and the suspension was aged for $1 \mathrm{~h}$ at room temperature. After filtering and drying at $110{ }^{\circ} \mathrm{C}$ overnight, the catalysts were calcined at $300{ }^{\circ} \mathrm{C}$ for $4 \mathrm{~h}\left(\right.$ ramp rate $\left.20{ }^{\circ} \mathrm{C} \mathrm{min}{ }^{-1}\right)$ in nitrogen.

Sol immobilization catalysts were prepared following the well-established procedure reported previously. ${ }^{36}$ In a typical catalyst synthesis $\left(1 \% \mathrm{Au} / \mathrm{TiO}_{2}\right)$ aqueous solutions of $\mathrm{HAuCl}_{4}$. $3 \mathrm{H}_{2} \mathrm{O}$ of the desired concentrations, stabilizing agent (PVA/ PVP) (1 wt\% aqueous solution) and an aqueous solution of $\mathrm{NaBH}_{4}(0.1 \mathrm{M})$ were prepared. To an aqueous $\mathrm{HAuCl}_{4}$ solution of the desired concentration, the required amount of a PVA solution (1 wt\%) was added, followed by further addition of $\mathrm{NaBH}_{4}$ solution $(0.1 \mathrm{M})$ to form a dark purple sol. After $30 \mathrm{~min}$ of sol generation, the colloid was immobilized by addition of the support material $\left(\mathrm{TiO}_{2}\right.$, Degussa P25). After $1 \mathrm{~h}$ of stirring, 
2 drops of concentrated $\mathrm{H}_{2} \mathrm{SO}_{4}$ was added to bring the solution to $\mathrm{pH} 2-3$. After $2 \mathrm{~h}$, the slurry was filtered, and the catalyst was washed thoroughly with $2 \mathrm{l}$ of distilled water (until the mother liquor was neutral $\mathrm{pH}$ ), followed by drying step at $120{ }^{\circ} \mathrm{C}$ overnight.

\section{Catalyst treatment}

For standard solvent treatment the following protocol was used: catalyst $(250 \mathrm{mg}$ ) was placed in a round bottomed flask (250 ml) equipped with magnetic stirrer, condenser and water $(125 \mathrm{ml})$. The mixture was heated to $90{ }^{\circ} \mathrm{C}$ in an oil bath and the treatment performed for 30,60, 120, $240 \mathrm{~min}$. The powder was recovered by filtration and dried at $110{ }^{\circ} \mathrm{C}$ for $16 \mathrm{~h}$. If calcination was carried out, the catalyst was calcined in static air for $4 \mathrm{~h}$ at different temperatures $\left(20{ }^{\circ} \mathrm{C} \min ^{-1}\right.$ ramp rate $)$.

\section{Catalyst testing}

Catalysts were investigated for CO oxidation using a fixed bed glass reactor with $3 \mathrm{~mm}$ internal diameter placed in a thermostatic bath $\left(25^{\circ} \mathrm{C}\right) .5000 \mathrm{ppm} \mathrm{CO}$ in air was fed to the reactor at rate controlled by electronic mass flow controllers and passed over the catalyst $(35 \mathrm{mg})$. CO oxidation product were analysed using a GC (1.5 m packed carbosieve column) equipped with an automated injection valve and a thermo conductivity detector (TCD).

TOF (turnover frequency) is expressed as:

$$
\mathrm{TOF}=\frac{\mathrm{mol}_{\mathrm{CO} \text { converted }}}{\mathrm{mol}_{\mathrm{Au}} \cdot h}
$$

\section{Diffuse reflectance infrared Fourier transform spectroscopy (DRIFT)}

All DRIFT spectra were recorded on a Bruker Tensor 27 spectrometer fitted with a HgCdTe (MCT) detector and a Harrick Praying Mantis HVC-DRP-4 cell equipped with $\mathrm{KBr}$ windows with the following settings: 64 scans, resolution $2 \mathrm{~cm}^{-1}$, aperture $4 \mathrm{~mm}$ in the 600 to $4000 \mathrm{~cm}^{-1}$ range. Spectra were compensated for gas phase water. Typically, the catalyst was placed in the cell

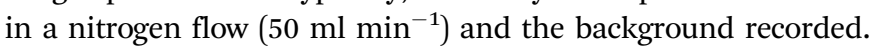
The flow composition was changed to $1 \% \mathrm{CO} / \mathrm{N}_{2}$ or $1 \% \mathrm{CO} / \mathrm{air}$ and a spectrum recorded after $10 \mathrm{~min}$ stabilization time. The resultant spectra were obtained through subtraction with a spectrum obtained from flowing $1 \% \mathrm{CO} / \mathrm{N}_{2}$ over $\mathrm{KBr}$. This was done to remove gas phase CO bands from the spectra.

\section{Diffuse reflectance UV-Vis spectroscopy}

Reflectance UV-Vis spectra were recorded on a Varian Cary 4000 spectrophotometer equipped with a Harrick Praying Mantis HVC-DRP-4 cell. The catalyst was placed in the cell and spectra were recorded in $\mathrm{N}_{2}$, air, $1 \% \mathrm{CO} / \mathrm{N}_{2}$ or $1 \% \mathrm{CO} /$ air $\left(50 \mathrm{ml} \mathrm{min}^{-1}\right)$.

\section{$\mathrm{X}$ ray photoelectron spectrscopy (XPS)}

XPS measurements were made on a Kratos Axis Ultra DLD spectrometer using monochromatic $\mathrm{Al} \mathrm{K}_{\alpha}$ radiation $(120 \mathrm{~W}$ source power). An analyser pass energy of $160 \mathrm{eV}$ was used for survey scans, while $40 \mathrm{eV}$ was employed for detailed regional scans. Samples were mounted using double-sided adhesive tape, and binding energies were referenced as discussed in the text.

\section{Transmission electron microscopic (TEM)}

Analysis was performed in a JEOL 2100 TEM instrument. The powdered samples were dispersed in deionised water before being added to holey carbon film on copper grids. EDX analysis was performed using Oxford Instruments SDD detector XmaxN 80T and analysed using Aztec software. Particle size distributions were determined using ImageJ software and min 350 particles for one sample were counted.

\section{Results and discussion}

To illustrate the effective use of $\mathrm{CO}$ as a probe to elucidate the effectiveness of capping agent removal treatments, we have reproduced the methodology for removal of PVA from sol immobilised $\mathrm{Au} / \mathrm{TiO}_{2}$, under reflux conditions using water, as reported by Hutchings and co-workers. ${ }^{16}$ In addition we applied the same protocol for $\mathrm{Au} / \mathrm{TiO}_{2}$ catalysts prepared with PVP capping agent. Therefore $1 \mathrm{wt} \% \mathrm{Au} / \mathrm{TiO}_{2}$ made by sol immobilization and stabilised by PVA (SI-PVA) or PVP (SI-PVP) were both treated with water at $90{ }^{\circ} \mathrm{C}$ for a range of times. As a control experiment to investigate the effect of reflux treatment on "naked" supported Au particles (i.e. supported gold nanoparticles formed in the absence of any stabiliser ligands), $\mathrm{Au} / \mathrm{TiO}_{2}$ was also prepared by deposition precipitation (DP) and subjected to the same reflux treatment.

Fig. 1 shows the effect of the reflux treatment time on the subsequent catalysts capability to oxidise $\mathrm{CO}$ at ambient temperature. This provides an indication to the effectiveness of the reflux treatment and provides a point of correlation with pre-existing literature on PVA removal. ${ }^{16}$ The substantial improvement in activity with $30 \mathrm{~min}$ reflux treatment observed for SI-PVA correlates

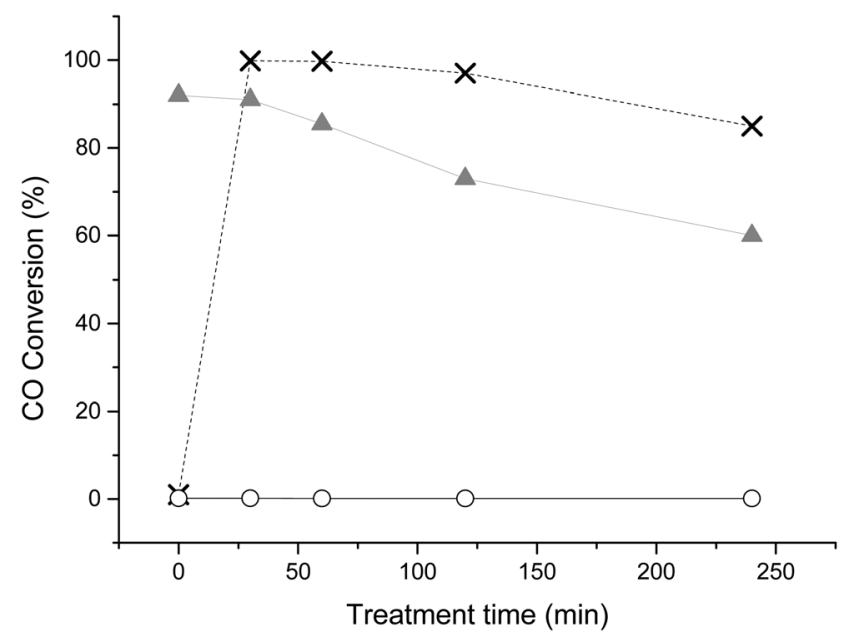

Fig. 1 TOF as a function of catalyst treatment time under reflux conditions $\left(\mathrm{GHSV}=12000 \mathrm{~h}^{-1}\right.$, catalyst $(35 \mathrm{mg}), t=30 \mathrm{~min}$, treatment performed at $90{ }^{\circ} \mathrm{C}$ ). SI-PVA: $\times$, SI-PVP: O, DP: $\Delta$ 
well to previous studies. Interestingly, increasing reflux time to greater than $2 \mathrm{~h}$ resulted in a decrease in activity of the SI-PVA catalyst. The catalyst prepared by DP also showed deactivation upon prolonged treatment in water, demonstrating that the reflux treatment slowly changes the nature of $\mathrm{Au}$ particles. When SI-PVP catalyst was treated with water, no activity for CO oxidation was observed, implying that the treatment was ineffective at removing the capping agent. One of the reasons for the inefficiency of the water treatment on the PVP-stabilized catalyst is the higher degree of interaction between polymer and the gold nanoparticles. This can be explained by the 'softer', i.e. more polarizable, behaviour of the nitrogen lone pair, that determines its higher affinity with gold.

One of the most effective methods of capping agent removal is catalyst calcination. However, elevated temperatures will result in metal migration and consequently particle sintering, negating the effect of capping agent removal. ${ }^{37}$ Thermal treatment in air has been reported to enhances the performance of PVAstabilised Au nanoparticles (AuNPs) in the oxidation of CO and also the removal of PVP from PVP-stabilised Pt nanoparticles using calcination at $500{ }^{\circ} \mathrm{C}$, though it was demonstrated that decomposition products were still present on the nanoparticles. ${ }^{38}$ The $\mathrm{Au} / \mathrm{TiO}_{2}$ catalysts prepared in this study were subjected to calcination performed at different temperatures, with the results for $\mathrm{CO}$ oxidation reported in Fig. 2. The results show that the calcination treatment is partially effective in activating the $1 \mathrm{wt} \% \mathrm{Au} / \mathrm{TiO}_{2}$ catalyst for $\mathrm{CO}$ oxidation. In the case of polymer-stabilized catalysts a minimum temperature of $500{ }^{\circ} \mathrm{C}$ calcination is required to activate them for $\mathrm{CO}$ oxidation. The effect of calcination on the activity of the DP catalyst is immediately apparent, with activity dropping significantly after $300{ }^{\circ} \mathrm{C}$ calcination. It is well known that increasing the calcination temperature of $\mathrm{Au} / \mathrm{TiO}_{2}$ leads to an increase in particle size, resulting in a lower amount of active sites and inactive gold particles. ${ }^{25,39}$ It is interesting to note that SI-PVP showed higher activity when calcined at $500{ }^{\circ} \mathrm{C}$

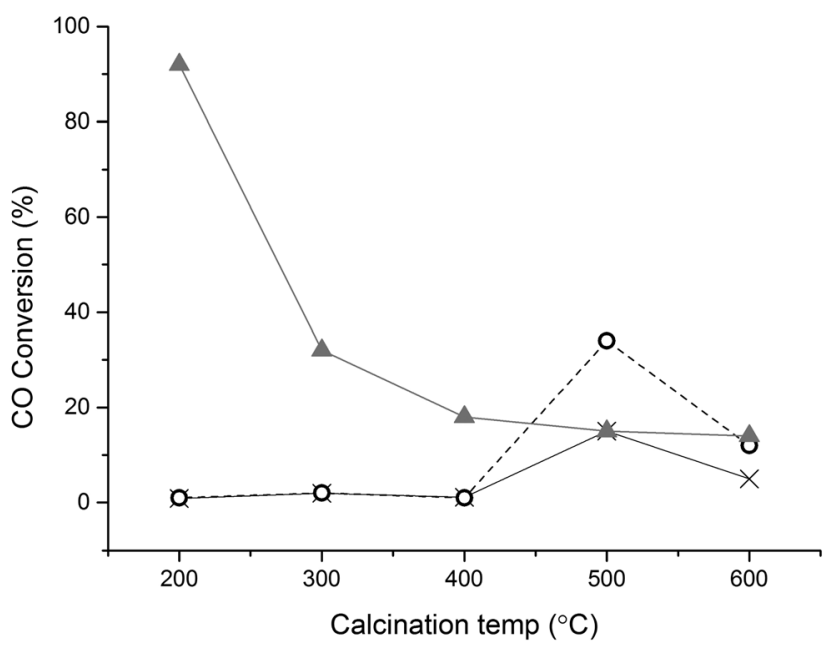

Fig. 2 Influence of the calcination temperature on catalyst activity in $\mathrm{CO}$ oxidation reaction; NC: not calcined, SI-PVP: O, SI-PVA: $\times$, DP: A Reaction conditions: $T=294 \mathrm{~K}, \mathrm{GHSV}=12000$. Calcination time $4 \mathrm{~h}$, ramp rate $20{ }^{\circ} \mathrm{C} \min ^{-1}, t=30 \mathrm{~min}$.
Table 1 Particle size distribution data form TEM, IR band position of adsorbed $\mathrm{CO}$ and UV-Vis SPR shift on addition of $\mathrm{CO}$ of $1 \% \mathrm{Au} / \mathrm{TiO}_{2}$ catalysts fresh and after treatment

\begin{tabular}{lllll}
\hline $\begin{array}{l}\text { Catalyst } \\
\text { preparation }\end{array}$ & Treatment & $\begin{array}{l}\text { Mean } \\
(\mathrm{nm})\end{array}$ & $\begin{array}{l}\text { IR CO band } \\
\left(\mathrm{cm}^{-1}\right)\end{array}$ & $\begin{array}{l}\text { UV SPR shift } \\
(\Delta \mathrm{nm})\end{array}$ \\
\hline SI-PVA & Fresh & 1.9 & $2122( \pm 1.0)$ & $3.6( \pm 0.6)$ \\
& Refluxed & 2.0 & $2106( \pm 1.0)$ & $9.8( \pm 2.1)$ \\
& Calcined & 3.9 & $2116( \pm 0.3)$ & $7.5( \pm 1.0)$ \\
SI-PVP & Fresh & 2.1 & $\mathrm{n} / \mathrm{a}$ & $0.4( \pm 0.6)$ \\
& Refluxed & 2.6 & $2122( \pm 3.8)$ & $2.1( \pm 0.9)$ \\
& Calcined & 4.3 & $2113( \pm 2.1)$ & $5.9( \pm 2.1)$ \\
DP & Fresh & 2.0 & $2106( \pm 0.8)$ & $10.3( \pm 0.7)$ \\
& Refluxed & 2.9 & $2107( \pm 1.7)$ & $8.1( \pm 0.8)$ \\
& Calcined & 3.9 & $2112( \pm 1.5)$ & $5.9( \pm 1.3)$
\end{tabular}

${ }^{a}$ Data is an average of 3 experiments with the associated error being the standard deviation. SI-PVA (sol immobilization-PVA), SI-PVP (sol Immobilization-PVP), DP (deposition precipitation), refluxed for $1 \mathrm{~h}$ at $90{ }^{\circ} \mathrm{C}$, calcined at $500{ }^{\circ} \mathrm{C}, 4 \mathrm{~h}$.

than the DP or SI-PVA catalyst. This is possibly due two factors, the first being the higher decomposition temperature of PVP, i.e. an increased stabilising effect of the metal particles, and the second the presence of different decomposition products on the metal, leading to a higher degree of poisoning in the case of the PVA stabilised catalyst. ${ }^{38,40}$

TEM analysis (Table 1) of the freshly prepared catalysts, refluxed for $1 \mathrm{~h}$ and calcined at $500{ }^{\circ} \mathrm{C}$ was performed to gain an insight into changes in particle size with respect to treatment and catalyst type. Both PVA and PVP sol-immobilisation preparations and the deposition precipitation preparation gave the expected small $\mathrm{Au}$ particle size and narrow size distributions, observed previously. ${ }^{41,42}$ Refluxed catalysts were all found to have a slightly increased mean particle size, though the degree of agglomeration was not consistent between preparation techniques. SI-PVA Au particle size increased by a marginal $4 \%$ after reflux treatment, the SI-PVP a more significant 23\% particle size increase and the DP a greater increase of $49 \%$. Even greater particle size increases were observed on $500{ }^{\circ} \mathrm{C}$ calcination with all catalysts having mean particle sizes of $c a .4 \mathrm{~nm}$. XPS analysis of all catalysts before and after treatments showed that the surface $\mathrm{Au}$ species where consistently metallic $\mathrm{Au}^{0}$ ( $\mathrm{Au} 4 \mathrm{f}$ binding energies of $83.4 \mathrm{eV} \pm 0.2 \mathrm{eV})($ ESI, $\dagger$ Fig. S1)

DRIFTS of all catalysts primarily showed bands associated with $\mathrm{TiO}_{2}$ and physisorbed water. In addition bands associated with PVA and PVP (C-N, O-H and C-H modes) can be detected in the $1500-1430 \mathrm{~cm}^{-1}$ region (ESI, $\dagger$ Fig. $\mathrm{S} 2$ ). These weak bands were found to disappear after heat treatment at $500{ }^{\circ} \mathrm{C}$, which correlates with the improved CO oxidation activity. The effect of the reflux treatments were much harder to determine with very little change being observed for the SI-PVA catalyst before and after treatment. From the $\mathrm{CO}$ oxidation data it is evident that the reflux treatment is successful in exposing Au sites. This demonstrates the insensitivity of this technique in determining subtler changes in ligand concentration.

Information about the local environment of the gold particles could be determined from the SPR band using diffuse reflectance 

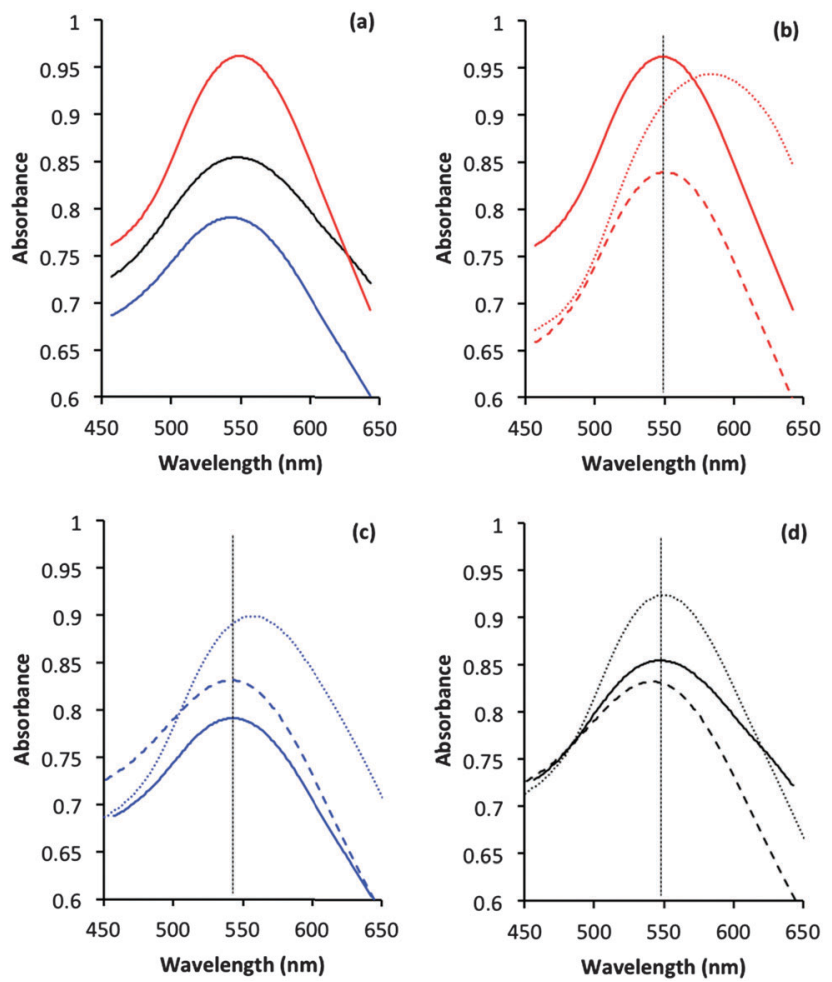

Fig. 3 Diffuse reflectance UV-Vis spectra of the $\mathrm{Au} / \mathrm{TiO} \mathrm{O}_{2}$ catalysts before and after thermal and reflux treatments. (a) Comparison of Au plasmon bands from SI-PVP (red), SI-PVA (blue) and DP (black) catalysts before treatment. (b-d) Comparison of original Au plasmon band (solid line), the plasmon band after reflux (dashed line) and calcination (dotted line) treatments for SI-PVA (b), SI-PVA (c) and DP (d) catalysts. Vertical black dotted lines in $(b-d)$ highlight original band positions before treatments.

UV-Vis. The wavelength range between 500 to $600 \mathrm{~nm}$, where the SPR band of Au nanoparticles is frequently observed, ${ }^{43}$ was monitored for the fresh and treated catalysts (Fig. 3). The plasmon band position arises from the interaction of an electromagnetic wave whose frequency matches that of the surface electrons. As discussed in the introduction, its position is influenced by many parameters such as polarization of the metal, adsorption of molecules and size/shape of the metal nanoparticles. $^{30}$ SPR positions in the three untreated catalysts are similar with only small $(5 \mathrm{~nm})$ variance between samples. It is known that both sol-immobilization and deposition precipitation techniques provide particles with a low aspect ratio and with similar particle size distributions. ${ }^{41,42,44}$ The similar particle sizes observed by TEM (Table 1) for these catalysts correlate well with the literature and also the relative invariance of SPR position observed by UV-Vis.

The position of the SPR band for all catalysts did not change position (within error) after the water treatment (Fig. 3). The catalytic data (Fig. 1) demonstrated that PVA was removed from the SI-PVA catalyst after water reflux treatment, while the strongly bound PVP was not. Taking this into account the SPR position has been shown to be relatively insensitive to changes in capping agent concentration. Substantive changes in SPR band position were observed in the case of the calcined sol-immobilisation catalysts, with an evident red shift after calcination. Intriguingly there was no comparable change in SPR band position on calcination of the DP catalyst. The relatively small observed increase in particle sizes from TEM of ca. $2 \mathrm{~nm}$ to $4 \mathrm{~nm}$ would not be expected to result in a significant red shift, as previous studies that correlated the particle size effect on SPR noted changes over differences of 10-40 $\mathrm{nm} \mathrm{Au}$ particle size, which are much more significant increase than we observe. ${ }^{43}$ The significant SPR shift seen with the sol-immobilised catalysts could be associated with residual species from the decomposition of the PVA or PVP protecting ligands on calcination. It is clear that shifts in SPR are not sufficiently sensitive to detect changes in ligand concentration after reflux treatments and are also complicated by other factors, as observed for the SPR band shifts with the calcined catalysts.

Information obtained from direct measurements of the catalysts by DRIFT and UV-Vis spectroscopy did not provide direct evidence of changes in Au coverage by capping agents. The only evidence for effective capping agent removal was from the CO oxidation data, which as previously discussed cannot be unequivocally attributed to capping agent removal. Therefore, we investigated the effect of capping agent removal treatments on the adsorption of the probe molecule $\mathrm{CO}$ onto $\mathrm{Au}$.

Exposure of the Si-PVA, SI-PVA and DP Au/ $/ \mathrm{TiO}_{2}$ catalysts to a $1 \% \mathrm{CO} / \mathrm{N}_{2}$ was monitored by DRIFTS, with band positions associated with $\mathrm{CO}$ adsorbed on the Au nanoparticles being shown in Table 1 (the spectra are shown in Fig. S3 (ESI $\dagger$ )). The DP catalyst provides an effective model system with which to correlate potential changes in the Au-CO IR bands before and after treatment by factors unrelated to capping agents. Such as changes due to growth in Au particle size, enhanced metal support interactions and the formation of polarised Au sites. ${ }^{22}$ The latter can mostly be discounted as XPS showed no change in $\mathrm{Au}$ binding energy for $\mathrm{DP} \mathrm{Au} / \mathrm{TiO}_{2}$ or the other catalysts after ligand removal treatments.

No change in CO band position was observed between the untreated and refluxed DP catalysts. However, calcination of the DP $\mathrm{Au} / \mathrm{TiO}_{2}$ catalyst at $500{ }^{\circ} \mathrm{C}$, resulted in a discernible (greater than the determined error of measurements $(c a . \pm 1.5)$ ) $+5.5 \mathrm{~cm}^{-1}$ change in $\mathrm{CO}$ band position in relation to the untreated catalyst. This could be attributed to enhanced metalsupport interaction on $500{ }^{\circ} \mathrm{C}$ heat treatment or the increase in particle size.

It is interesting to note that the fresh untreated SI-PVA material adsorbed CO, while showing no activity for CO oxidation. This is plausible as the gold surface is not completely covered by the polymer, and that CO could interact with the surface. However, access is clearly hindered as demonstrated by lower values of activity in the CO oxidation reaction and that the band for adsorbed CO is located at a much higher wavenumber $\left(2116 \mathrm{~cm}^{-1}\right)$ than for the untreated DP catalyst $\left(2106 \mathrm{~cm}^{-1}\right)$. This high wavenumber absorbance for CO on SI-PVA indicates a low CO coverage of the metal surface, i.e. a smaller active surface. Water reflux treatment of the SI-PVA catalyst results in a clear and sharp $\mathrm{CO}$ band at a lower wavenumber relative to untreated SI-PVA, 
equivalent to that seen for CO on the DP catalyst. This indicates a higher coverage of the surface with most of the surface is available for $\mathrm{CO}$ adsorption and oxidation, when in the presence of oxygen. Calcination of the SI-PVA catalyst resulted in a CO band wavenumber slightly lower than the untreated SI-PVA, indicating increased chemical interaction between bound $\mathrm{CO}$ due to an increase in exposed $\mathrm{Au}$ sites. However, this blue shift was mediated by the increase in Au particle size as observed on calcination of the DP catalyst.

The SI-PVP catalyst does not show any bands for adsorbed $\mathrm{CO}$ in the case of the untreated catalyst. The coverage of the surface by PVP seems more complete, and that is possibly due to the stronger polymer-gold interaction. Treatment in water does have a slight influence on the layer of polymer, with a weak CO band at high a wavenumber of $2122 \mathrm{~cm}^{-1}$. The very high wavenumber position of this band suggests a very low surface coverage of CO. This is in good agreement with the catalytic data (Fig. 1). The only treatment that significantly modifies the adsorption properties of the SI-PVP catalyst is the calcination. CO binds to surface of gold with the band located at $2113 \mathrm{~cm}^{-1}$, a wavenumber similar to all the calcined catalysts.

It is possible to correlate the wavenumber of adsorbed $\mathrm{CO}$, indicative of the coverage of the $\mathrm{Au}$ particle by $\mathrm{CO}$, with the catalytic data for CO oxidation (Fig. 4). This shows that only the catalysts where the adsorbed $\mathrm{CO}$ band is present at wavenumbers lower than $2116 \mathrm{~cm}^{-1}$ are active for the oxidation of CO. Below this threshold a strong relationship between activity and CO band wavenumber is observed, with the most active catalyst having the lowest frequency CO band. According to the results reported by Boccuzzi et al. this trend could be explained by the different coverage of $\mathrm{CO}$ within the $2102-2115 \mathrm{~cm}^{-1}$ region $\left(13 \mathrm{~cm}^{-1}\right)$ shift, while more blue shifted bands seen for untreated SI-PVA are to be attributed to partially positive $\mathrm{Au}^{\delta+}$ sites. ${ }^{25}$ Of note is that such $\mathrm{Au}^{\delta+}$ sites have been reported to be present in catalysts that have very low activity for CO oxidation. ${ }^{29,45}$ Therefore, while there is a compelling case to associate increases in activity with

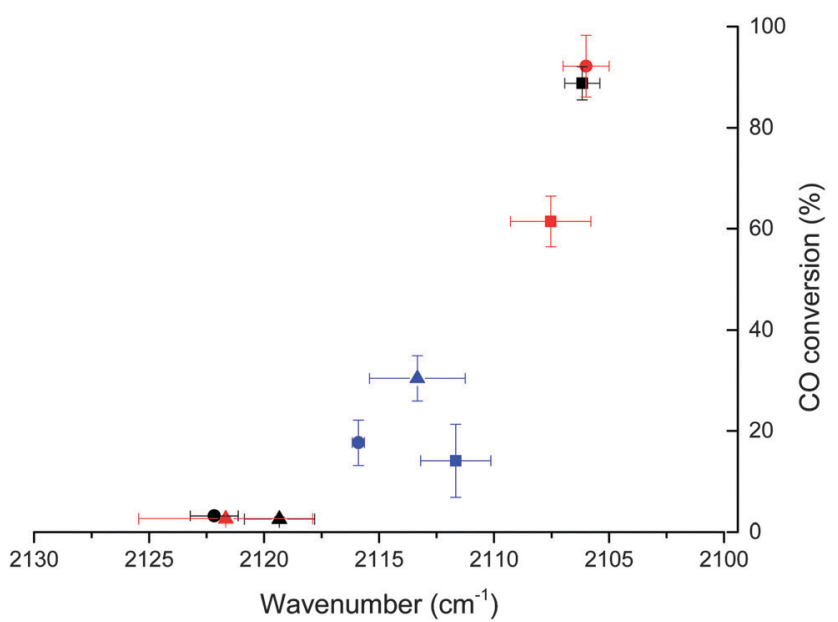

Fig. 4 CO conversion plotted against position of the adsorbed $\mathrm{CO}$-band in DRIFT. Key: DP, SI-PVA and $\Delta$ SI-PVP catalysts. Black symbols denote as prepared catalysts, red symbols after $1 \mathrm{~h}$ reflux and blue symbols after $500{ }^{\circ} \mathrm{C}$ heat treatment. only an increase in $\mathrm{Au}$ exposure (i.e. increased $\mathrm{CO}$ coverage and corresponding chemical shift) changes in the charge of Au sites cannot be ignored. XPS suggests that there is no significant charged $\mathrm{Au}$ species on any of the catalysts and that the changes in $\mathrm{Au}$ exposure are the predominant reason for the $\mathrm{CO}$ band positions.

\section{CO as a probe molecule: a UV-Vis study}

As discussed in the introduction an alternative method of elucidating CO concentration has been to monitor the shift in the $\mathrm{Au}$ SPR after exposure. Therefore we explored the possibility of using this effect to monitor the accessibility of CO on the Au surface. As with the studies for CO probe in situ IR spectroscopy, we initially investigated the DP catalyst as a control sample. The UV-Vis spectra of the DP catalyst was first taken under an atmosphere of flowing $\mathrm{N}_{2}$ before the gas was switched to $1 \% \mathrm{CO} / \mathrm{N}_{2}$ and the UV-Vis spectra taken again (Fig. 5 and Table 1). A noticeable blue shift of $10.3 \mathrm{~nm}$ was observed upon addition of CO, which shown to be reversible when the atmosphere reverted back to pure $\mathrm{N}_{2}$. This is similar to observations by Sirinakis et al. for Au supported on yttrium stabilised zirconia, but interestingly the current shift was observed at room temperature, while the previous paper used a temperature of $400{ }^{\circ} \mathrm{C} .{ }^{34}$ Hypotheses about the causes of this shift are an injection of charge into the nanoparticle by carbon monoxide or a change in the dielectric constant and of the refractive index of the nanoparticle's environment. After similar experiments on the refluxed and calcined DP samples it was observed that the blue shift, on the addition of CO to the system, was less significant with these samples. A shift of 8.1 and $5.9 \mathrm{~nm}$ was observed for the refluxed and calcined DP samples respectively. The observed blue SPR shifts correlated well with the observed particle sizes from TEM analysis, with a linear decrease in SPR shift with particle size (Fig. 6).

The blue SPR shift observed for the SI-PVA catalysts (Table 1 and Fig. S4, ESI $\dagger$ ) did not show the same correlation with particle size as observed with the DP catalysts, with the untreated SI-PVA showing the lowest SPR shift despite having the smallest particle size. This is not surprising, as CO has limited interaction with the Au surface due to the PVA ligand hindering access. As with the DRIFTS study the slight SPR shift indicates that the Au surface is not totally inaccessible, though it is significantly obstructed. After reflux treatment the SPR shift increases to a value comparable with the untreated DP catalyst, providing direct evidence that the reflux treatment on SI-PVA increases accessibility of Au sites. Calcination of the SI-PVA resulted in an increased Au surface exposure to CO, relative to the untreated sample, but this is limited by the increase in particle size.

As with SI-PVA the SPR shift observed for the SI-PVP catalyst (Table 1 and Fig. S4, ESI $\dagger$ ) did not show the same trend with particle size (as seen for the DP catalyst) due to a similar blocking of CO access to Au by the PVP ligand. As noted with the DRIFTS study the PVP Au sites appear to be almost entirely inaccessible on the untreated sample, with almost no SPR shift observed. Reflux treatment did result in a small SPR shift being observed, though this was still smaller than that seen for untreated SI-PVA. This corresponds to previous observations 


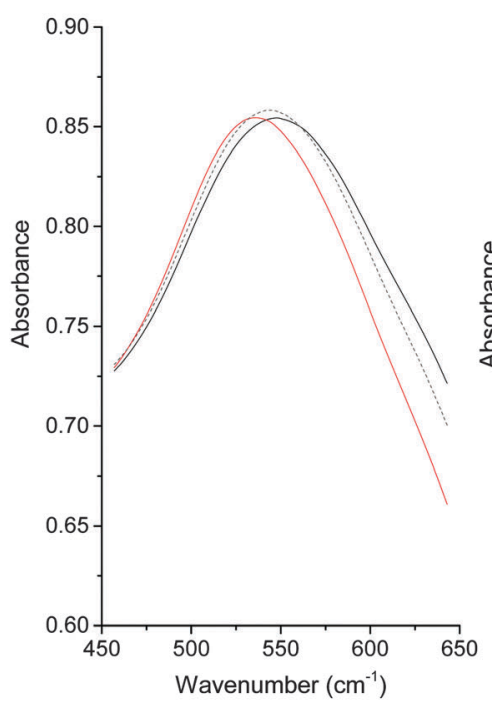

b

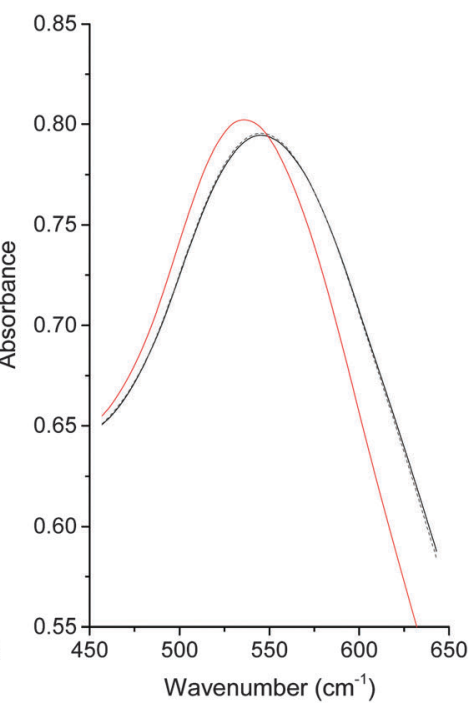

c

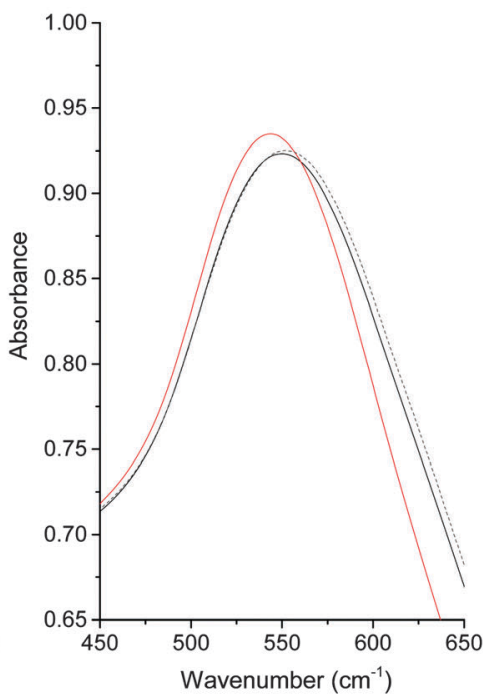

Fig. 5 UV-Vis analysis of catalyst under $\mathrm{N}_{2}$ (black), $0.5 \% \mathrm{CO} / \mathrm{N}_{2}$ (red) and returning to a $\mathrm{N}_{2}$ (black dots) environment: 1 wt\% Au/TiO 2 catalysts before treatment (a), after $1 \mathrm{~h}$ reflux (b) and calcination at $500{ }^{\circ} \mathrm{C}$ (c).

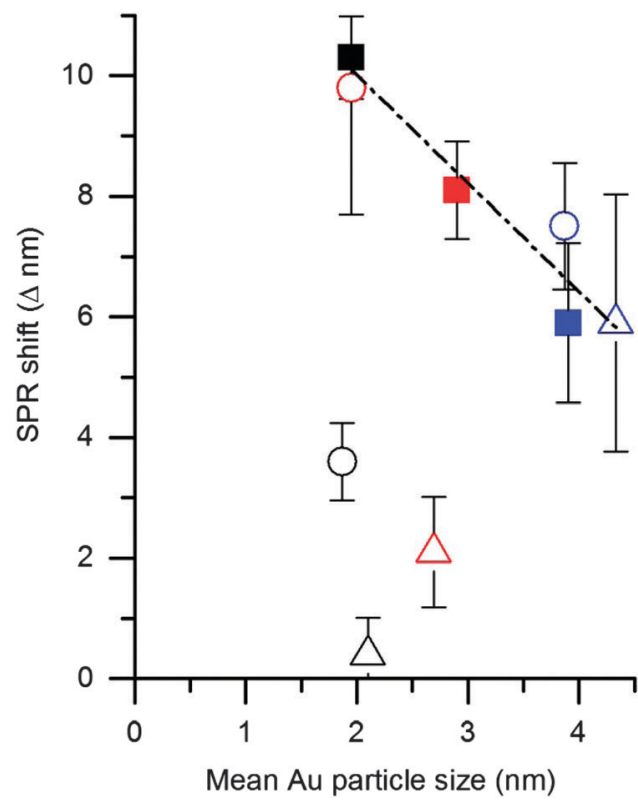

Fig. 6 Correlation of change in Au SPR on addition of $1 \% \mathrm{CO} / \mathrm{N}_{2}$ with $\mathrm{Au}$ mean particle size (determined by TEM). Key: DP, $-\mathrm{SI}-\mathrm{PVA}$ and $\Delta \mathrm{SI}-$ PVP catalysts. Black symbols denote as prepared catalysts, red symbols after $1 \mathrm{~h}$ reflux and blue symbols after $500{ }^{\circ} \mathrm{C}$ heat treatment.

that reflux treatments on PVP stabilised Au nanoparticles is ineffectual. Only after the ligand has been removed by calcination did the SPR shift become discernible.

Taking the above observations into account it can be seen that all catalysts with effective CO access to the Au surface lie on the same trend line when plotting $\Delta$ SPR vs. mean Au particle size (Fig. 7), while those with poor CO accessibility do not follow the same correlation. The plasmon shift observed upon addition

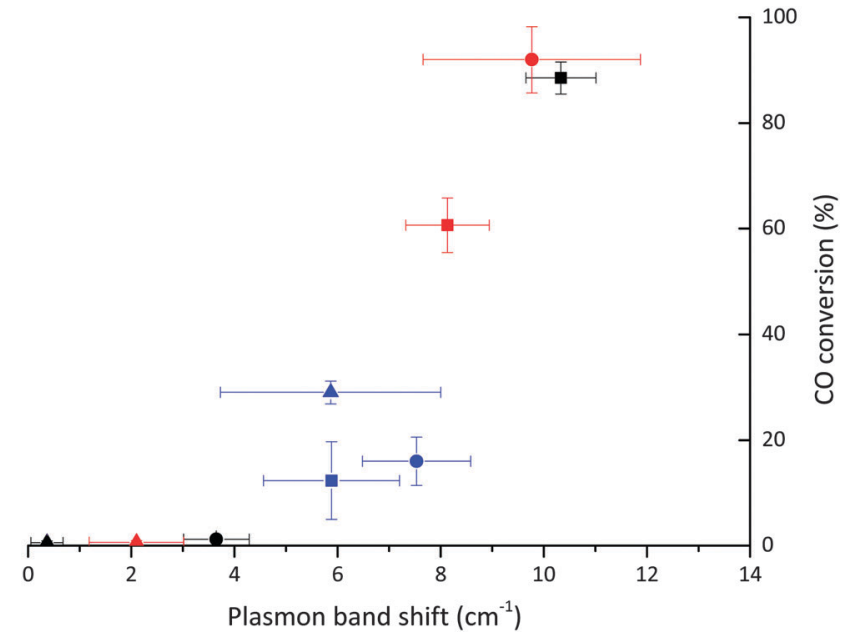

Fig. $7 \mathrm{CO}$ conversion as a function of the plasmon shift for $1 \% \mathrm{Au} / \mathrm{TiO}_{2}$ catalysts between $\mathrm{N}_{2}$ and CO/N $/ \mathrm{N}_{2}$. Key: $\mathrm{DP}, \boldsymbol{\mathrm { SI }}$-PVA and $\Delta \mathrm{SI}-\mathrm{PVP}$ catalysts. Black symbols denote as prepared catalysts, red symbols after $1 \mathrm{~h}$ reflux and blue symbols after $500{ }^{\circ} \mathrm{C}$ heat treatment.

of CO can also be correlated with the activity of the catalyst for ambient CO oxidation (Fig. 7). The relationship between greater SPR shift and higher CO oxidation activity corroborates with the relationship between IR band position and activity, showing that accessibility of Au sites can be determined by UV-Vis and IR studies with $\mathrm{CO}$ as a probe molecule.

\section{Conclusions}

A range of $1 \mathrm{wt} \% \mathrm{Au} / \mathrm{TiO}_{2}$ catalysts prepared by sol-immobilisation with PVA and PVP stabilising ligands and a control deposition 
precipitation prepared $1 \mathrm{wt} \% \mathrm{Au} / \mathrm{TiO}_{2}$ catalyst were subjected to reflux and thermal treatments. The fresh and treated catalysts were tested for CO oxidation. As expected the DP catalyst was most active before any treatment while the PVA catalyst became active after the reflux treatment but the PVP catalyst remained inactive, until a calcination treatment. Ex situ DRIFTS and UV-Vis spectroscopic analysis provided limited information on the effect of ligand removal treatments. DRIFTS showed a loss of bands associated with the polymer after calcination but the subtler effects of reflux treatment could not be followed, due to the weak nature of the original polymer bands. Ex situ UV-Vis spectroscopy showed changes in the position of the Au surface plasmon band after treatment but a number of complicated factors, such as residual carbon deposition after calcination, made association with ligand removal unfeasible. In situ DRIFTS with CO as a probe molecule, showed that the band position of $\mathrm{CO}$ adsorbed on $\mathrm{Au}$ shifted between 2106 and $2122 \mathrm{~cm}^{-1}$ depending on the catalyst and the ligand removal treatment. Shifts were attributed to changes in CO interaction in relation to surface coverage, with lower wavenumber bands being associated with higher CO coverage. In situ UV-Vis spectroscopy showed that a reversible shift in the SPR occurred on the addition of $\mathrm{CO}$ gas to the $\mathrm{Au} / \mathrm{TiO}_{2}$ catalysts. Here the CO surface coverage could be correlated to the size of the SPR shift on CO addition, greater SPR shift correlating with increased CO coverage. Both techniques can therefore be applied to determining the success of ligand removal treatments by monitoring the change in accessible $\mathrm{Au}$ sites for CO adsorption. Correlation of SPR shift or CO band position in IR with activity for $\mathrm{CO}$ oxidation showed that increased CO surface coverage corresponded with higher CO conversion, validating the methods as a way of monitoring the effectiveness of ligand removal.

\section{Acknowledgements}

We would like to acknowledge the support of the UK Catalysis Hub. Also we would like to acknowledge Dr Georgi Lalev (Cardiff University, School of Optometry and Vision Sciences) for the transmission electron microscopy.

\section{References}

1 M. Haruta, T. Kobayashi, H. Sano and N. Yamada, Chem. Lett., 1987, 405-408, DOI: 10.1246/cl.1987.405.

2 G. J. Hutchings, J. Catal., 1985, 96, 292-295.

3 T. Hayashi, K. Tanaka and M. Haruta, J. Catal., 1998, 178, 566-575.

4 J. K. Edwards, B. Solsona, E. N. N, A. F. Carley, A. A. Herzing, C. J. Kiely and G. J. Hutchings, Science, 2009, 323, 1037-1041.

5 M. D. Hughes, Y. J. Xu, P. Jenkins, P. McMorn, P. Landon, D. I. Enache, A. F. Carley, G. A. Attard, G. J. Hutchings, F. King, E. H. Stitt, P. Johnston, K. Griffin and C. J. Kiely, Nature, 2005, 437, 1132-1135.
6 A. Abad, P. Concepcion, A. Corma and H. Garcia, Angew. Chem., Int. Ed., 2005, 44, 4066-4069.

7 D. I. Enache, J. K. Edwards, P. Landon, B. Solsona-Espriu, A. F. Carley, A. A. Herzing, M. Watanabe, C. J. Kiely, D. W. Knight and G. J. Hutchings, Science, 2006, 311, 362-365.

8 C. Baatz and U. Pruesse, J. Catal., 2007, 249, 34-40.

9 R. Zanella, S. Giorgio, C. R. Henry and C. Louis, J. Phys. Chem. B, 2002, 106, 7634-7642.

10 N. Dimitratos, A. Villa, C. L. Bianchi, L. Prati and M. Makkee, Appl. Catal., A, 2006, 311, 185-192.

11 N. Dimitratos, F. Porta and L. Prati, Appl. Catal., A, 2005, 291, 210-214.

12 S. A. Kondrat, G. Shaw, S. J. Freakley, Q. He, J. Hampton, J. K. Edwards, P. J. Miedziak, T. E. Davies, A. F. Carley, S. H. Taylor, C. J. Kiely and G. J. Hutchings, Chem. Sci., 2012, 3, 2965-2971.

13 M. Comotti, C. Della Pina, R. Matarrese and M. Rossi, Angew. Chem., Int. Ed., 2004, 43, 5812-5815.

14 M. Comotti, C. Della Pina, E. Falletta and M. Rossi, Adv. Synth. Catal., 2006, 348, 313-316.

15 Z. Niu and Y. Li, Chem. Mater., 2014, 26, 72-83.

16 J. A. Lopez-Sanchez, N. Dimitratos, C. Hammond, G. L. Brett, L. Kesavan, S. White, P. Miedziak, R. Tiruvalam, R. L. Jenkins, A. F. Carley, D. Knight, C. J. Kiely and G. J. Hutchings, Nat. Chem., 2011, 3, 551-556.

17 S. M. Ansar, F. S. Ameer, W. Hu, S. Zou, C. U. Pittman Jr and D. Zhang, Nano Lett., 2013, 13, 1226-1229.

18 S. O. Blavo, E. Qayyum, L. M. Baldyga, V. A. Castillo, M. D. Sanchez, K. Warrington, M. A. Barakat and J. N. Kuhn, Top. Catal., 2012, 1-8.

19 S. Albonetti, A. Lolli, V. Morandi, A. Migliori, C. Lucarelli and F. Cavani, Appl. Catal., B, 2015, 163, 520-530.

20 Z. Wu, D.-e. Jiang, A. K. P. Mann, D. R. Mullins, Z.-A. Qiao, L. F. Allard, C. Zeng, R. Jin and S. H. Overbury, J. Am. Chem. Soc., 2014, 136, 6111-6122.

21 D. Yates, J. Colloid Interface Sci., 1969, 29, 194-204.

22 P. Dumas, R. Tobin and P. Richards, J. Electron. Spectrosc. Relat. Phenom., 1986, 39, 183-189.

23 J. France and P. Hollins, J. Electron. Spectrosc. Relat. Phenom., 1993, 64, 251-258.

24 F. Boccuzzi, A. Chiorino, S. Tsubota and M. Haruta, J. Phys. Chem., 1996, 100, 3625-3631.

25 F. Boccuzzi, A. Chiorino, M. Manzoli, P. Lu, T. Akita, S. Ichikawa and M. Haruta, J. Catal., 2001, 202, 256-267.

26 F. Boccuzzi, S. Tsubota and M. Haruta, J. Electron. Spectrosc. Relat. Phenom., 1993, 64, 241-250.

27 C. Ruggiero and P. Hollins, J. Chem. Soc., Faraday Trans., 1996, 92, 4829.

28 M. A. Bollinger and M. A. Vannice, Appl. Catal., B, 1996, 8, 417-443.

29 J.-D. Grunwaldt, M. Maciejewski, O. S. Becker, P. Fabrizioli and A. Baiker, J. Catal., 1999, 186, 458-469.

30 P. Mulvaney, Langmuir, 1996, 12, 788-800.

31 M. Ando, T. Kobayashi, S. Iijima and M. Haruta, J. Mater. Chem., 1997, 7, 1779-1783. 
32 M. Ando, T. Kobayashi, S. Iijima and M. Haruta, Sens. Actuators, B, 2003, 96, 589-595.

33 M. Ando, T. Kobayashi and M. Haruta, Catal. Today, 1997, 36, 135-141.

34 G. Sirinakis, R. Siddique, I. Manning, P. H. Rogers and M. A. Carpenter, J. Phys. Chem. B, 2006, 110, 13508-13511.

35 P. J. Miedziak, Q. He, J. K. Edwards, S. H. Taylor, D. W. Knight, B. Tarbit, C. J. Kiely and G. J. Hutchings, Catal. Today, 2011, 163, 47-54.

36 S. Meenakshisundaram, E. Nowicka, P. J. Miedziak, G. L. Brett, R. L. Jenkins, N. Dimitratos, S. H. Taylor, D. W. Knight, D. Bethell and G. J. Hutchings, Faraday Discuss., 2010, 145, 341-356.

37 S. Albonetti, T. Pasini, A. Lolli, M. Blosi, M. Piccinini, N. Dimitratos, J. A. Lopez-Sanchez, D. J. Morgan,
A. F. Carley, G. J. Hutchings and F. Cavani, Catal. Today, 2012, 195, 120-126.

38 Y. Du, P. Yang, Z. Mou, N. Hua and L. Jiang, J. Appl. Polym. Sci., 2006, 99, 23-26.

39 E. D. Park and J. S. Lee, J. Catal., 1999, 186, 1-11.

40 O. W. Guirguis and M. T. Moselhey, Nat. Sci., 2012, 4, 57-67.

41 M. Haruta, Catal. Today, 1997, 36, 153-166.

42 N. Dimitratos, J. A. Lopez-Sanchez, D. Morgan, A. Carley, L. Prati and G. J. Hutchings, Catal. Today, 2007, 122, 317-324.

43 S. Eustis and M. A. El-Sayed, Chem. Soc. Rev., 2006, 35, 209-217.

44 M. Haruta, S. Tsubota, T. Kobayashi, H. Kageyama, M. J. Genet and B. Delmon, J. Catal., 1993, 144, 175-192.

45 S. Daniells, A. Overweg, M. Makkee and J. Moulijn, J. Catal., 2005, 230, 52-65. 